ORIGINAL ARTICLE

\title{
Anemia among School-Age Children: Magnitude, Severity and Associated Factors in Pawe Town, Benishangul-Gumuz Region, Northwest Ethiopia
}

\author{
Muluken Birhanu ${ }^{1}$, Lealem Gedefaw ${ }^{2}$, Yaregal Asres ${ }^{2 *}$
}

\footnotetext{
OPEN ACCESS

Citation: Muluken Birhanu, Lealem Gedefaw, Yaregal Asres. Anemia among School-Age Children: Magnitude, Severity and Associated Factors in Pawe Town, Benishangul-Gumuz Region, Northwest Ethiopia. Ethiop J Health Sci.2017;28(3):259.

doi:http://dx.doi.org/10.4314/ejhs.v28i3.3

Received: November 15, 2017

Accepted: November 17, 2017

Published: May 1, 2018

Copyright: (C) 2018 Muluken Birhanu, et

al . This is an open access article

distributed under the terms of the

Creative Commons Attribution License,

which permits unrestricted use,

distribution, and reproduction in any

medium, provided the original author and source are credited.

Funding: Assosa University, Ethiopia

Competing Interests: The authors

declare that this manuscript was approved

by all authors in its form and that no

competing interest exists.

Affiliation and Correspondence:

${ }^{1}$ Departemnt of Medical Laboratory

Science, College of Health

Science, Assosa University, Assosa, Ethiopia

${ }^{2}$ School of Medical Laboratory

Science, Institute of Health, Jimma

University, Jimma, Ethiopia

*Email: yaregala3@gmail.com;

yaregal.asres@ju.edu.et
}

\section{ABSTRACT}

BACKGROUND: Anemia is a global public health problem associated with increased mortality and morbidity. The cause of anemia in school-age children is multifactorial and has been associated with delayed psychomotor development, poor cognitive performance, impaired immunity and decrease working capacity. The aim of this study was to determine the magnitude, severity and determinant factors of anemia among school-age children (5-15 years) in Pawe Town, Northwest Ethiopia.

METHODS: A community based cross-sectional study was conducted from March 20 to June 19, 2015 in Pawe Town. A total of 422 school-age children were included in this study. Sociodemographic and related data were collected using structured questionnaire. Anthropometric data were collected from each study participant. Hemoglobin concentration was measured using HemoCue $^{\circledR}$ Hb $201^{+}$System (HemoCue, Angelholm, Sweden). Blood film for malaria diagnoses and stool examination for intestinal parasites were also performed. Data were analyzed using SPSS version 20.0.

RESULTS: The overall prevalence of anemia among school-age children was 33.9\%. Mothers' illiteracy (AOR=7.5, 95\% CI: 2.616.3), being from a family with low income $(A O R=4.8,95 \%$ CI: 1.3-10.9), being stunted (AOR=7.1, 95\% CI: 2.9-11.9), being underweight (AOR=5.3, 95\% CI: 2.1-13.3), infection with intestinal parasites (AOR=5.2, 95\% CI: 2.1-12.6), and malaria infection (AOR=8.2, 95\% CI: 1.8-14.5) were identified as associated factors of anemia.

CONCLUSION: In this study, anemia is a moderate public health problem among school-age children. School health strategies and interventions targeting nutritional deficiencies and parasitic infections might be very important.

KEYWORDS: Anemia, Associated factors, School-age children, Pawe Town, Ethiopia 


\section{INTRODUCTION}

Anemia is a condition where there is a reduction of hemoglobin $(\mathrm{Hb})$ level in the blood, resulting in lower quantity of oxygen transported via blood for physiological need (1). Anemia is a global public health problem and affects $24.8 \%$ of the world population (2). Anemia is a major public health problem among women and children; school-age children are one of the groups for whom it is common (3). Anemia also continues to be a major public health problem in Ethiopia. The Ethiopian Demographic and Health Survey (EDHS) key indicator at different times reported the prevalence of anemia among children from 44-56\% (4-6). There are different root causes of anemia which include increased red blood cell (RBC) destruction due to malaria, blood loss due to helminthiasis and hemorrhage, reduced $\mathrm{RBC}$ production due to nutritional deficiencies of iron, vitamin $\mathrm{B}_{12}$ and chronic infections. Although anemia has a variety of causes, it is generally assumed that $50 \%$ of its causes is iron deficiency (7-12).

Anemia has a negative impact in the physical, mental and cognitive development of children. Besides, it has economic impact by increasing impairment of lives and disability, reduction in intellectual capacity and loss of productivity due to increased morbidity from infectious diseases $(13,14)$. In Ethiopia, most studies on anemia and micronutrient interventions were focused on pregnant women and pre-school children. Even though few local studies showed anemia prevalence, national representative data are not available on school-age children particularly in our study area. To mitigate the impacts of anemia, there is a need to emphasis this segment of the population using schools as a practical platform to deliver an integrated package of interventions. To do so, evidence based development of possible strategies and intervention for the problem will have eminent contribution, which needs an effective surveillance and monitoring. Without these steps, we cannot go anywhere. Therefore, the aim of this study was to determine the magnitude, severity and associated factors of anemia among school-age children in Pawe Town, Benshangul-Gumuz Region.

\section{MATERIALS AND METHODS}

Study design and setting: A community based prospective cross sectional study was conducted in Pawe Town, Metekel Zone, Benishnagul-Gumuz Region, Northwest Ethiopia, from March 20 to June 19,2015 . The town is located $557 \mathrm{Km}$ away from Addis Ababa at $11^{0} 19^{\prime} 59.47^{\prime \prime} \mathrm{N}$ latitude and $36^{0} 25^{\prime} 00.66^{\prime \prime}$ E longitude with an average altitude of 1050-1250 meters above sea level. The estimated population of Pawe Town was 3,522 and 880 households, an average of 4 persons per household. The area has been highly endemic for malaria (15).

The sample size was estimated using single population proportion formula by the following assumptions: $95 \%, \quad 5 \%$ and $50 \%$ level of confidence, margin of error and proportion $(\mathrm{P})$, respectively. Households were selected using systematic sampling technique from all the three Kebeles (smallest administrative units) in the town (Figure 1). A total of 422 school-age children, between 5-15 years, living in Pawe Town were included in the study. On the other hand, children on treatment of anemia were excluded from the study.

Data collection techniques and instruments: Interviewer based structured questionnaire was used to collect socio-demographic and related data. Height and weight were measured according to standard anthropometric methods (16). Height was measured to the nearest 0.1 centimeters in bare feet standing upright against the Seca height measuring tape. Weight was measured to the nearest 0.1 kilogram using a digital scale. During weight measurement, study participants wore underwear and T-shirt only. Weight and height were measured twice and the mean value was used for the analysis.

Capillary blood was collected from each participant for $\mathrm{Hb}$ and peripheral blood preparation. $\quad \mathrm{HemoCue}^{\circledR} \mathrm{Hb} \quad 201^{+}$System (HemoCue, Angelholm, Sweden) was used to 


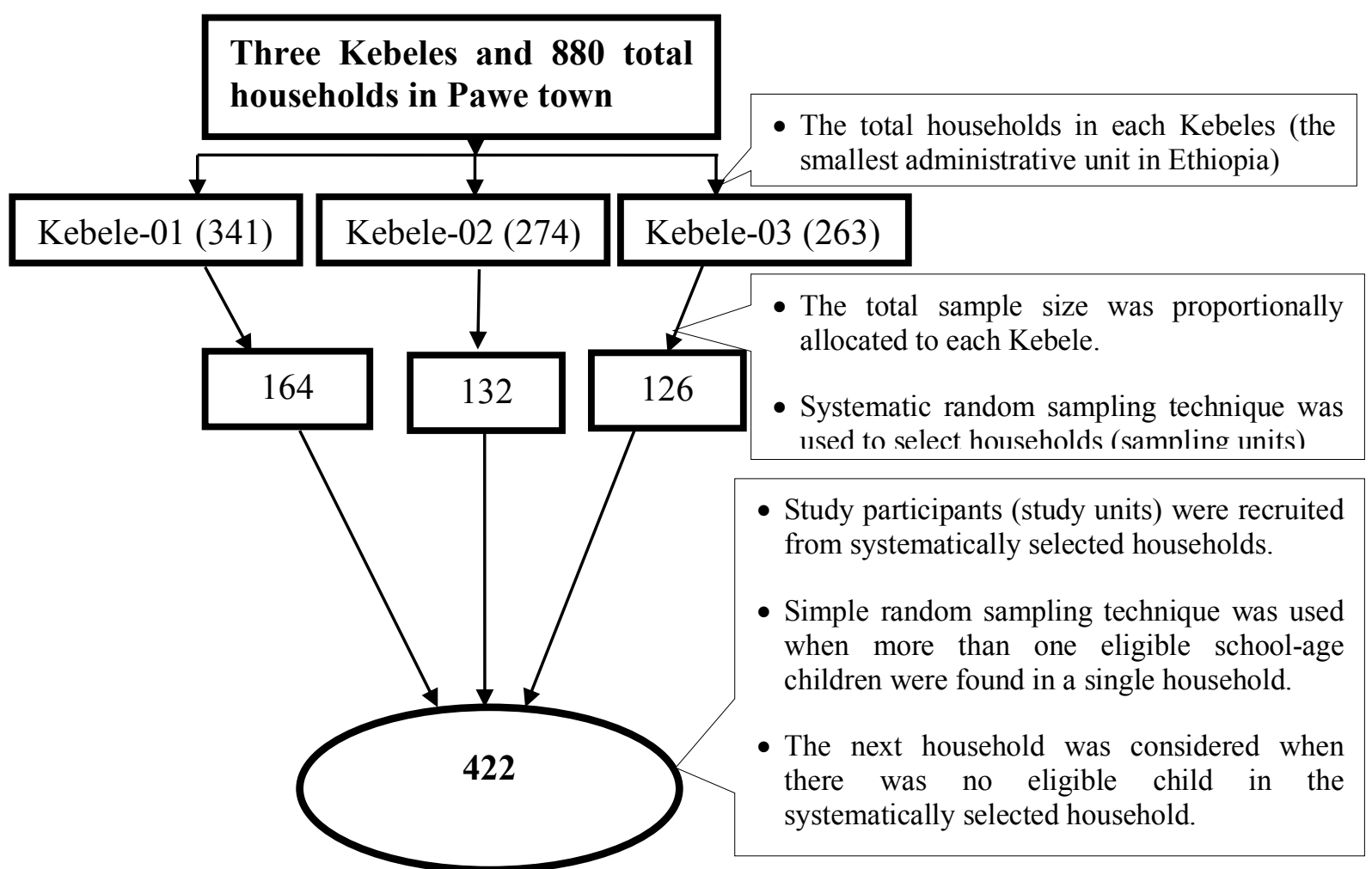

Figure 1: Sampling technique among school-age children living in Pawe Town, Northwest Ethiopia, 2015.

determine $\mathrm{Hb}$ concentration. Free flowing capillary blood was allowed to enter the microcuvette. The cuvette was placed into the cuvette holder for photometric quantitative readout of $\mathrm{Hb}$ concentration in $\mathrm{g} / \mathrm{dL}$. Both thick and thin blood films were prepared from each study participants and stained with Giemsa stain. Blood films were examined for hemoparasites. Stool sample was collected from each study participant using leak-proof and clean stool cup. Stool samples were examined for intestinal parasitic infection using both direct wet mount and formol-ether concentration techniques.

To assure the quality of data, training was given for data collectors. Supervision was made daily during the data collection period. All the laboratory activities were performed following standard operating procedures and manufacturers' instruction. Expiry dates of all laboratory reagents were checked.

Data analysis and interpretation: Z-scores for each study participant were calculated using
World Health Organization (WHO) anthroPlus1.0.4 statistical software for age between 5-15 years. Children who had less than -2 Z-scores (-2SD) values were considered under nutrition (17). $\mathrm{Hb}$ concentration was adjusted for altitude (18). Anemia was defined based on WHO $\mathrm{Hb}$ concentration cut-off value after adjusted for altitude (1). Study participants with $\mathrm{Hb}$ concentration $<11.5 \mathrm{~g} / \mathrm{dL}$ and $12 \mathrm{~g} / \mathrm{dL}$ were considered as anemic for 6-11 and 12-15 years old children, respectively. Mild anemia was defined as $\mathrm{Hb}$ concentration between $10 \mathrm{~g} / \mathrm{dL}$ and $12 \mathrm{~g} / \mathrm{dL}$ in males and between $10 \mathrm{~g} / \mathrm{dL}$ and $11.5 \mathrm{~g} / \mathrm{dL}$ in females. Moderate and severe anemia were defined when $\mathrm{Hb}$ concentration was between 7 $\mathrm{g} / \mathrm{dL}$ and $9.9 \mathrm{~g} / \mathrm{dL}$ and $<7 \mathrm{~g} / \mathrm{dL}$, respectively. All the data were initially entered and cleaned using Epi-data version 3.1 and then exported to SPSS version 20.0 for analysis. Descriptive statistics was done to indicate the frequency of the variables. Multivariable logistic regression analysis was used to identify the associated factors 
of anemia. All variables with $\mathrm{P}$ value $<0.05$ were considered as statistically significant.

Ethical consideration: Ethical approval was obtained from Assosa University Ethical Review Board. Official permission was obtained from Pawe Woreda Health Bureau to conduct the study. Informed written consent was taken from the parents/guardians. Moreover, assent was obtained from each child greater than 7 years old. The data collected from the participants will remain anonymous for indefinite period of time. All the study participants who were found positive for intestinal parasites, had malaria and were anemic were treated free of charge at Pawe General Hospital, Northwest Ethiopia.

\section{RESULT}

Socio-demographic characteristics of the study participants: Four hundred and twenty-two study participants were participated in this study of whom $54.0 \%(n=228)$ were female. The majority of the study participants, $87.9 \%(n=371)$, were in the age group of 5-11 years. The mean age of the study participants was $8.32 \pm 2.42$ years. Most of the children's mothers, $69.9 \%,(n=295)$ and $82.9 \%$ $(n=350)$, were illiterate and housewives, respectively (Table 1 ).

Table 1: Socio-demographic characteristics of school-age children living in Pawe Town, Northwest Ethiopia, $2015(\mathrm{n}=422)$

\begin{tabular}{llll}
\hline Variables & Categories & Frequency & Percentage \\
\hline Age (years) & $5-11$ & 371 & 87.9 \\
Sex & $12-15$ & 51 & 12.1 \\
\multirow{3}{*}{ Mother's occupation } & Male & 194 & 46.0 \\
& Female & 228 & 54.0 \\
& House wife & 350 & 82.9 \\
& Merchant & 25 & 5.9 \\
Father's occupation & Daily labor & 10 & 2.4 \\
& Employed & 37 & 8.8 \\
& Farmer & 71 & 16.8 \\
& Merchant & 131 & 31.0 \\
& Daily labor & 134 & 31.8 \\
Mother's education & No job & 54 & 12.8 \\
\multirow{2}{*}{ Father's education } & Employed & 32 & 7.6 \\
\multirow{3}{*}{ Monthly household income (ETB) } & Illiterate & 295 & 69.9 \\
& Literate & 127 & 30.1 \\
& Illiterate & 195 & 46.2 \\
Family size & Literate & 227 & 53.8 \\
& $<500$ & 173 & 41.0 \\
& $500-1999$ & 190 & 45.0 \\
\hline
\end{tabular}

ETB: Ethiopian Birr

Nutritional and clinical characteristics of the study participants: Among the total study participants, $34.4 \%(n=145)$ were stunted for their age while $32.2 \% \quad(\mathrm{n}=136)$ were underweight. Regarding intestinal parasites, 30.8\% $(n=130)$ of the children had intestinal parasites from whom,
Hymenolepis nana, $45.4 \% \quad(\mathrm{n}=59)$, took the highest proportion followed by Hookworm, 26.9\% $(n=35)$. Twenty-nine $(6.9 \%)$ of the study participants were infected with $P$. falciparum malaria (Table 2). 
Table 2: Nutritional and clinical characteristics of school-age children living in Pawe Town, Northwest Ethiopia, $2015(\mathrm{n}=422)$

\begin{tabular}{llll}
\hline Variables & & Frequency & Percentage \\
\hline Stunting (Z-score $<-2 \mathrm{SD})$ & & 145 & 34.4 \\
Underweight (Z-score $<-2 \mathrm{SD})$ & & 136 & 32.2 \\
Intestinal parasites infection & & 130 & 30.8 \\
Type of intestinal parasite & H. nana & 59 & 45.4 \\
$(\mathrm{n}=130)$ & Hookworm & 35 & 26.9 \\
& G. lamblia & 20 & 15.4 \\
& S. mansoni & 3 & 2.3 \\
& H. nana and G. lamblia & 8 & 6.2 \\
P. falciparum & H. nana and Hookworm & 5 & 3.8 \\
\hline
\end{tabular}

SD: Standard devation; H. nana: Hymenolepis nana; G. lamblia: Giardia lamblia; S. mansoni: Schistosoma mansoni; P. falciparum: Plasmodium falciparum

Prevalence and associated factors of anemia: The mean $\mathrm{Hb}$ value of school-age children was $12.06 \pm 1.20 \mathrm{~g} / \mathrm{dL}$. The overall prevalence of anemia was $33.9 \%(\mathrm{n}=143)$, from whom, $86.7 \%$ $(\mathrm{n}=124)$ and $13.3 \%(\mathrm{n}=19)$ had mild and moderate anemia, respectively. After adjusting for all the measured explanatory variables in the multivariable regression model, mother education $(\mathrm{AOR}=7.5,95 \% \mathrm{CI}: 2.6-16.3)$, being from a family with low income $(\mathrm{AOR}=4.8,95 \% \mathrm{CI}$ : 1.3 10.9), being stunted (AOR $=7.1,95 \% \mathrm{CI}: 2.9$ $11.9)$, being underweight $(\mathrm{AOR}=5.3,95 \% \mathrm{CI}$ : 2.1-13.3), having intestinal parasite infection $(\mathrm{AOR}=5.2,95 \% \mathrm{CI}: 2.1-12.6)$ and being infected by $P$. falciparum malaria (AOR $=8.2,95 \%$ CI: 1.8-14.5) were significantly associated with anemia (Table 3).

\section{DISCUSSION}

The aim of this study was to determine the prevalence of anemia and associated factors among school-age children living in Pawe Town, Northwest Ethiopia. Accordingly, more than one third of school-age children had anemia. Anemia was a moderate public health problem in the study area.

The prevalence of anemia in our study was higher compared with similar studies done in Denizli Turkey (19), Vietnam (20), Qinghai and Ningxia elementary schools in China (21), Serbia (22), Cape Verde (23), Kenitra Morroco (24),
Kersa Eastern Ethiopia (25), Filtu Town Somali Southeast Ethiopia (26), Durbete, Northwest Ethiopia (27) and Addis Ababa (28). The high prevalence of anemia in this study might be attributed to the high prevalence of intestinal parasites and malaria as compared with other studies. This indicates that there is a need to give an attention on this segment of the population using schools as a practical platform to deliver an integrated package of interventions to mitigate the magnitude and/or impacts of anemia in our study area.

The prevalence of anemia was significantly associated with certain socio-demographic characteristics of children and their families. Children from families with low monthly household income were more likely to be anemic compared with children from families with high monthly household income. This might be due to the fact that families with low monthly household income might not get enough iron-rich foods, and diets of children living in poor families are usually monotonous. Low income in the family thus limits the type and amount of food availablity. The finding corroborated the reports of similar studies conducted in Ningxia and Qinghai's poor counties of rural China (21), India $(29,30)$ and Edo State of Nigeria (31). Children who had illiterate mothers were more likely to be anemic compared to children whose mothers were literate. 
Table 3: Factors associated with anemia among school-age children in Pawe Town, Metekel Zone, NorthWest Ethiopia, 2015.

\begin{tabular}{|c|c|c|c|c|c|}
\hline \multirow[t]{2}{*}{ Variables } & \multirow[t]{2}{*}{ Categories } & \multicolumn{2}{|l|}{ Anemia } & \multirow[t]{2}{*}{ COR $(95 \% \mathrm{CI})$} & \multirow[t]{2}{*}{$\operatorname{AOR}(95 \% \mathrm{CI})$} \\
\hline & & $\begin{array}{l}\text { Yes } \\
\mathbf{N}(\%)\end{array}$ & $\begin{array}{l}\text { No } \\
\text { N(\%) }\end{array}$ & & \\
\hline \multirow{2}{*}{ Age (years) } & $5-11$ & $131(35.3)$ & $240(64.7)$ & $1.8(0.9-3.5)$ & $3(0.95-9.4)$ \\
\hline & $12-15$ & $12(23.5)$ & $39(76.5)$ & $\operatorname{Ref}(1)$ & $\operatorname{Ref}(1)$ \\
\hline \multirow[t]{2}{*}{ Sex } & Male & $72(37.1)$ & $122(62.9)$ & $1.3(0.87-1.96)$ & $1.15(0.55-2.4)$ \\
\hline & Female & $71(31.1)$ & $157(68.9)$ & $\operatorname{Ref}(1)$ & $\operatorname{Ref}(1)$ \\
\hline \multirow[t]{4}{*}{ Mother's occupation } & House wife & $130(37.1)$ & $220(62.9)$ & $4.9(1.7-14.1) \dagger$ & $3.6(0.8-16.1)$ \\
\hline & Merchant & $5(20.0)$ & $20(80.0)$ & $2.1(0.5-8.6)$ & $4.7(0.5-41.6)$ \\
\hline & Daily labor & $4(40.0)$ & $6(60.0)$ & $5.5(1.1-14.6)^{*}$ & $1.5(0.02-11.3)$ \\
\hline & Employed & $4(10.8)$ & $33(89.2)$ & $\operatorname{Ref}(1)$ & $\operatorname{Ref}(1)$ \\
\hline \multirow[t]{5}{*}{ Father's occupation } & Farmer & $27(38.0)$ & $44(62.0)$ & $2.7(0.97-7.3)$ & $1.1(0.2-6)$ \\
\hline & Merchant & $32(24.4)$ & 99 (75.6) & $1.4(0.5-3.7)$ & $2.1(0.4-10.9)$ \\
\hline & Daily labor & $54(40.3)$ & $80(59.7)$ & $2.9(1.1-7.6)^{*}$ & $1.4(0.3-7.3)$ \\
\hline & No job & $24(44.4)$ & $30(55.6)$ & $3.5(1.2-9.8)^{*}$ & $1.7(0.3-11.2)$ \\
\hline & Employed & $6(18.8)$ & $26(81.2)$ & $\operatorname{Ref}(1)$ & $\operatorname{Ref}(1)$ \\
\hline \multirow[t]{2}{*}{ Mother's education } & Illiterate & $126(42.7)$ & $169(57.3)$ & $4.8(2.7-8.5) \ddagger$ & $7.5(2.6-16.3) \ddagger$ \\
\hline & Literate & $17(13.4)$ & $110(86.6)$ & $\operatorname{Ref}(1)$ & $\operatorname{Ref}(1)$ \\
\hline \multirow[t]{2}{*}{ Father's education } & Illiterate & $77(39.5)$ & $118(60.5)$ & $1.6(1.1-2.4)^{*}$ & $1.5(0.7-3.5)$ \\
\hline & Literate & $66(29.1)$ & $161(70.9)$ & $\operatorname{Ref}(1)$ & $\operatorname{Ref}(1)$ \\
\hline household & $<500$ & $100(57.8)$ & $73(42.2)$ & $8.7(3.9-14.6) \dagger$ & $4.8(1.3-10.9)^{*}$ \\
\hline \multirow[t]{2}{*}{ (ETB) } & $500-1999$ & $35(18.4)$ & $155(81.6)$ & $1.44(0.6-3.3)$ & $1.4(0.4-5.1)$ \\
\hline & $\geq 2000$ & $8(13.6)$ & $51(86.4)$ & $\operatorname{Ref}(1)$ & $\operatorname{Ref}(1)$ \\
\hline \multirow[t]{2}{*}{ Family size } & $\leq 5$ & $44(29.7)$ & $104(70.3)$ & $\operatorname{Ref}(1)$ & $\operatorname{Ref}(1)$ \\
\hline & $>5$ & $99(36.1)$ & $175(63.9)$ & $1.3(0.9-2.1)$ & $1.73(0.8-3.9)$ \\
\hline \multirow[t]{2}{*}{ Intestinal parasite infection } & Yes & $89(68.5)$ & $41(31.5)$ & $9.5(6-15.4) \ddagger$ & $5.2(2.1-12.6) \ddagger$ \\
\hline & No & $54(18.5)$ & $238(81.5)$ & $\operatorname{Ref}(1)$ & $\operatorname{Ref}(1)$ \\
\hline \multirow[t]{2}{*}{ P. falciparum malaria } & Yes & $22(75.9)$ & $7(24.1)$ & $7(2.9-16.9) \$$ & $8.2(1.8-14.5) \ddagger$ \\
\hline & No & $121(30.8)$ & $272(69.2)$ & $\operatorname{Ref}(1)$ & $\operatorname{Ref}(1)$ \\
\hline \multirow[t]{2}{*}{ Stunting (Z-score <-2SD) } & Yes & $109(75.2)$ & $36(24.8)$ & $5.7(2.8-14.7) \ddagger$ & $7.1(2.9-11.9) \$$ \\
\hline & No & $34(12.3)$ & $243(87.7)$ & $\operatorname{Ref}(1)$ & $\operatorname{Ref}(1)$ \\
\hline \multirow[t]{2}{*}{ Underweight (Z-score $<-2 \mathrm{SD})$} & Yes & $102(75.0)$ & $34(25.0)$ & $7.9(3.7-18.2) \leftrightarrows$ & $5.3(2.1-13.3) \$$ \\
\hline & No & $41(14.3)$ & $245(85.7)$ & $\operatorname{Ref}(1)$ & $\operatorname{Ref}(1)$ \\
\hline
\end{tabular}

AOR: Adjusted Odd Ratio; CI: Confidence Interval; ETB: Ethiopian Birr; SD: Standard deviation; P. falciparum: Plasmodium falciparum; Ref: Reference; *: significant association at $P<0.05$; $\%$ significant association at $P<0.01$; $f$ significant association at $P<0.001$

A similar study conducted in Kenitra Morroco (24) also showed that anemia was significantly associated with mother education. Low level of mothers' education may affect children's nutritional status negatively. This might be related to lack of knowledge and awareness on the use of diversified diets including iron and other micronutrients.

The prevalence of anemia also changed according to the nutritional status of the children.
Stunted children were 7 times more likely to be anemic than non-stunted children, and underweight children were 5 times more likely to be anemic compared to children having normal weight. Our finding was in agreement with studies done in Punjab India (29), Tanzania (32), Kenya $(33,34)$ and Nigeria (35) which showed that anemia was significantly associated with malnutrition. This might be due to the fact that a diet containing low amount of bioavailable iron or

DOI: http://dx.doi.org/10.4314/ejhs.v28i3.3 
inadequate dietary iron intake and other micronutrient deficiency is one of the main causes of anemia particularly in children $(7,9,10)$.

In this study, the prevalence of anemia was significantly high in school-age children who had intestinal parasitic infection. This might be due to the fact that most intestinal parasites particularly hookworm have their own contribution to blood loss and/or red cell destruction and thus contribute to anemia. However, we did not assess the association of each parasite to anemia due to our sample size. Our finding was supported by studies reported from Tanzania (32) and Edo state Nigeria (31).

The prevalence of anemia was also significantly associated with malaria. Children infected with $P$. falciparum malaria were more likely to be anemic compared to none infected children. This finding is supported by the study done in Nigeria (35) which showed that anemia was significantly associated with malaria. The possible explanation for this could be that malaria is one of the major causes of anemia by causing increased destruction of both parasitized and unparasitized erythrocytes (immune-mediated hemolysis, phagocytosis, splenic sequestration) and by decreasing production of RBCs in the bone marrow (bone marrow suppression, inadequate reticulocyte production, effects of inflammatory cytokines and effects of parasite factors) (36).

The findings of this study should be interpreted in light of the following limitations. Since the study was cross-sectional in design, it was impossible to determine cause-effect relationships. Moreover, micronutrient among study participants was not assessed to identify the root causes of anemia.

In conclusion, more than one third of schoolage children were anemic. Anemia in this study was a moderate public health problem among school-age children. Mother's illiteracy, being from a family with low income, being stunted, being underweight, having intestinal parasite infection and being infected by $P$. falciparum malaria were identified as independent predictors of anemia. Multi-sectoral and integrated packages of interventions on identified determinant factors of anemia using schools as a platform for this segment of population will have imminent contribution to combat the problem.

\section{ACKNOWLEDGMENTS}

We would like to acknowledge the data collectors for their efforts. We also would like to thank the study participants and their parents who were volunteers to give all relevant information for the study. This study was financially supported by Assosa University.

\section{REFERENCES}

1. World Health Organization/United Nations University/UNICEF. Iron deficiency anemia, assessment, prevention and control: a guide for programme managers. Geneva: WHO, 2001.

2. WHO/CDC. Worldwide Prevalence of Anemia 1993-2005: WHO Global Database on Anemia. WHO, Geneva, Switzerland, 2008.

3. McLean E, Cogswell M, Egli I, Wojdyla D, Benoist B. Worldwide prevalence of anemia, WHO Vitamin and Mineral Nutrition Information System, 1993-2005. Public Health Nutr, 2009; 12(4) 444-454.

4. Central Statistical Agency/Ethiopia, ORC Macro. Ethiopia Demographic and Health Survey 2005. Addis Ababa, Ethiopia: Central Statistical Agency/Ethiopia and ORC Macro, 2006.

5. Central Statistical Agency/Ethiopia, ICF International. 2011 Ethiopia Demographic and Health Survey: Key Findings. Calverton, Maryland, USA: CSA and ICF International, 2012.

6. Central Statistical Agency (CSA)/Ethiopia and ICF. Ethiopia Demographic and Health Survey 2016: Key Indicators Report. Addis Ababa, Ethiopia and Rockville, Maryland, USA.CSA and ICF, 2016.

7. Van den Broek NR, Letsky EA. Etiology of anemia in pregnancy in south Malawi. Am J Clin Nutr, 2000; 72(suppl 1):247S-256S.

8. Van Eijik AM, Ayisi JG, Terkuile FO. Malaria and human immunodeficiency virus infection as risk factor for anemia in infants in Kisumu, Western Kenya. Am J Trop Med Hyg, 2002; 67(1):44-53.

9. Black RE, Morris SS, Bryce J. Where and why are 10 million children dying every year? Lancet, 2003; 361: 2226-2234.

10. Halterman JS, Kaczorowski JM, Aligne CA, et al. Iron deficiency and cognitive achievement among school-aged children and adolescents in the United States. Pediatrics, 2001; 107 (6):1381-1386. 
11. Beard JL. Iron requirements in adolescent females. J Nutr. 2000; 130(25 Suppl): 440-442.

12. Asobayire FS, Adou P, Davidsson L, et al. Prevalence of iron deficiency with and without concurrent anemia in population groups with high prevalence of malaria and other infections: a study in Cote d'ivoire. Am J Clin Nutr, 2001; 74(6): 776.

13. Grantham-Mc, Gregor S, Ani C. A review of studies on the effect of iron deficiency on cognitive development in children. J Nutr, 2001; 131(2): 649-666.

14. Nelson M. Anemia in adolescent girls: effects on cognitive function and activity. Proc Nutr Soc, 1996; 55(1B): 359-67.

15. President's Malaria Initiative. Malaria Operational Plan (MOP) Ethiopia. FY 2008.

16. Marfell-Jones M, Olds T, Stew A, Carter L. International standards for anthropometric assessment. Australia: The International Society for the Advancement of Kinanthropometry, 2006.

17. World Health Organization. Physical status: the use and interpretation of anthropometry, Reports of WHO expert committee, Technical Report Series. Geneva, Switzerland, 1995; 854: 6-115.

18. Sullivan KM, Mei Z, Grummer-Strawn L, Parvanta I. Hemoglobin adjustments to define anemia. Trop Med Int Health, 2008; 13(10): 1267-1271.

19. Işık Balcı Y, Karabulut A, Gürses D, Ethem Çövüt İ. Prevalence and Risk Factors of Anemia among Adolescents in Denizli, Turkey. Iran J Pediatr, 2012; 22(1): 77-81.

20. Le HT, Brouwer ID, Verhoef H, et al. Anemia and intestinal parasite infection in school children in rural Vietnam. Asia Pac J Clin Nutr, 2007; 16 (4): 716-723.

21. Luo R, Zhang L, Liu Ch, et al. Anemia in Rural China's Elementary Schools: Prevalence and Correlates in Ningxia and Qinghai's Poor Counties. J Health Popul Nutr, 2011; 29(5): 471.

22. Djokic D, Drakulovic MB, Radojicic Z, et al. Risk factors associated with anemia among Serbian school-age children 7-14 years old: results of the first national health survey. Hippokratia, 2010; 14(4): 252-260.

23. Semedo M, Santos M, Baião M, Luiz R, Veiga G. Anemia and associated factors among school-age children in Cape Verde, West Africa. AJFAND, 2014; 14(7): 9511-9528.

24. Hioui M, Ahami A, Aboussaleh Y, Rusinek S et al. Risk factor of anemia among school age children in Kenitra Morocco. East Afr J Public Health, 2008; 5(2): 62-66.
25. Mesfin F, Berhane Y, Worku A. Anemia among Primary School Children in Eastern Ethiopia. PLoS One, 2015; 10(4): 1-10.

26. Gutema B, Adissu W, Asres Y, Gedefaw L. Anemia and associated risk factors among school age children in Filtu town, Somalia region, Southeast Ethiopia. BMC Hematol, 2014; 14(1): 1.

27. Alelign T, Degarege A, Erko B. Prevalence and factors associated with undernutrition and anemia among school children in Durbete Town, Northwest Ethiopia. Arch Public Health, 2015; 73(1): 1-7.

28. Mekasha A, Zerfu M. Determine the prevalence of anemia among school children and adolescents in Addis Ababa. Ethiop Med J.2009; 47(2): 129.

29. Gupta VK, Maria AK, Kumar R, et al. the Prevalence of Anemia in Young Males and Females with Respect to the Age, Body Mass Index (BMI), Activity Profile and the Socioeconomic Status in Rural Punjab. J Clin Diagn Res, 2011, 5(5): 1020-1026.

30. Jain N, Jain MV. Prevalence of anemia in school children in Rishikesh, Uttrakhand, India. Med Pract Rev, 2012; 3(1): 1-4.

31. Osazuwa F, Ayo OM, Imade P. Contribution of malnutrition and malaria to anemia in children in rural communities of Edo state, Nigeria. $N \mathrm{Am} \mathrm{J}$ Med Sci, 2010; 2(1): 532-536.

32. Tatala SR, Kihamia CM, Kyungu LH, et al. Risk factors for anemia in schoolchildren in Tanga Region, Tanzania. Tanzan J Health Res, 2008; 10 (4): $189-201$.

33. Pullan RL, Gitonga C, Mwandawiro C, et al. Estimating the relative contribution of parasitic infections and nutrition for anemia among schoolaged children in Kenya: a subnational geostatistical analysis. BMJ Open, 2013; 3(2):1-10.

34. LeenstraT, Kariuki SH, Kurtis JD, et al. Prevalence and severity of anemia and iron deficiency: crosssectional studies in adolescent schoolgirls in western Kenya. Eur J Clin Nutr, 2004; 58(4): 681.

35. Onimawo IA, Ukegbu PO, Asumugha VU, et al. Assessment of anemia and iron status of school age children (aged 7-12 years) in rural communities of Abia state, Nigeria. AJFAND, 2010; 10(5): 2570 2585.

36. Douglas JP, Tom W, Gregory CD. Severe Malarial Anemia: Innate Immunity and Pathogenesis. Int $J$ Biol Sci, 2011; 7(9):1427-1442.

DOI: http://dx.doi.org/10.4314/ejhs.v28i3.3 